\title{
RESEÑA
}

\section{Congreso Internacional SocyHume: "De la Sociabilidad al Patrimonio Histórico y Cultural” (Centro Interdisciplinar de História, Culturas e Sociedades, Universidad de Évora, Portugal, 2016)}

\author{
Fernando Anaya Gámez \\ Máster en Historia de la Masonería en España, Universidad Nacional de Educación a Distancia (UNED). \\ Profesor del IES El Chaparil de Nerja, España. Doctorando de Historia, Universidad de Málaga (UMA). \\ Miembro del Centro de Estudios Históricos de la Masonería Española (CEHME) de la Universidad de \\ Zaragoza, España. Correo electrónico: fanagam@gmail.com
}

DOI: http://dx.doi.org/10.15517/rehmlac.v8i2.26781

Fecha de recibido: 30 de octubre de 2016 - Fecha de aceptación: 13 de noviembre de 2016

El hombre es un ser naturalmente sociable, y que el que vive fuera de la sociedad por organización y no por efecto del azar, es ciertamente, o un ser degradado, o un ser superior a la especie humana.

Política. Libro I, Capítulo I, Aristóteles

\section{Introducción}

Decía el escritor, político y filósofo dublinés Edmund Burke que "la sociedad humana constituye una asociación de las ciencias, las artes, las virtudes y las perfecciones", $\mathrm{y}$ aunque el sentido planea en torno a sus particulares visiones sobre el momento histórico que vivió, no deja de ser concluyente sobre lo que nos trae a colación. Y es que, al igual que el Centro de Estudios Históricos de la Masonería Española (CEHME) y el Centro de Estudios Históricos de la Masonería Latinoamericana y Caribeña (CEHMLAC) han tenido siempre claro que en sus simposios pueden y deben entrar las múltiples ópticas de las disciplinas auxiliares que, sin lugar a dudas, enriquecen la ciencia historiográfica, en clara similitud paradigmática nos encontramos con la estructura que se presentó en el Congreso Internacional SocyHume que, bajo el título "Da sociabilidade ao património histórico e cultural. O Sul em perspectiva comparada, séculos XVIII a XXI", dio a conocer esta interesante iniciativa promovida desde el Centro Interdisciplinar de História, Culturas e Sociedades (CIDEHUS) de la Universidad de Évora, en Portugal, durante los días 22 al 24 de septiembre del presente año. Sirvan las presentes líneas para reflejar, con la brevedad requerida, cómo se desarrolló esta interesante reunión científica en los cálidos días de la histórica ciudad portuguesa. 


\section{Patrimonio y sociabilidad: de la teoría a la práctica}

No pretende esta reseña entrar en el debate o en la sana discusión científica sobre cómo la perspectiva histórica de la sociabilidad ha ido calando a lo largo y ancho de las diferentes realidades investigadoras, como en preclara maestría viene confrontándose en esta revista ${ }^{1}$ desde sus comienzos ${ }^{2}$, ni en cómo se ha contemplado ${ }^{3}$ y se contempla ${ }^{4}$ ésta desde su aterrizaje a finales de la centuria pasada en el caso español. Baste acercarse a la definición que del concepto historia nos propone la profesora Alicia Alted, proponiéndose ésta como el "conocimiento científico de la realidad social de un tiempo pasado remoto, mediato o inmediato desde el presente" ${ }^{, 5}$ para poner el foco de atención en el grado de aceptación actual.

La misión, por lo tanto, será la de describir o procurar la narración de cómo los estudios históricos de la masonería estuvieron presentes en este congreso. Y es que tenían que estarlo ${ }^{6}$, y no sólo por alusiones a Maurice Agulhon. Si bien la sobresaliente planificación trazada por la directora de este evento, la profesora María Zozaya Montes, albergó la posibilidad de congregar las vertientes de la sociabilidad en relación a la política,

\footnotetext{
${ }^{1}$ Entre los numerosos artículos que vienen focalizándose directa o indirectamente hacia la sociabilidad en sus diversos números semestrales, véase, como ejemplo, Miguel Guzmán-Stein, "En la Academia. Entrevista a la Dra. Céline Sala y al Dr. Yván Pozuelo Andrés: Estudios sobre la historia de la sociabilidad y de la masonería en España y Francia”, REHMLAC 2, no. 2 (diciembre 2010-abril 2011 [citado el 10 de octubre de 2016]): disponible en http://revistas.ucr.ac.cr/index.php/rehmlac/article/view/6604/6295

${ }^{2}$ Es interesante reseñar en este sentido tanto el excelso trabajo de la profesora Céline Sala que ha ido y sigue desarrollando desde el propio nacimiento de la revista, la línea de investigación que mantiene el profesor Éric Saunier, sin desdeñar a otros muchos investigadores, como la paradigmática inclusión de un capítulo monográfico que, bajo el título "Freemasonry, Sociabity and Power", en el número especial UCLA-Grand Lodge of California, evidenció el interés por esta vertiente dentro del mundo de la historiografía. Véase, como ejemplo, Ricardo Martínez Esquivel, "Sociabilidad, religiosidad y nuevas cosmovisiones en la Costa Rica del cambio de siglo (XIX - XX)", REHMLAC Special Issue UCLA-Grand Lodge of California (2013 [citado el 10 de octubre de 2016]): disponible en http://revistas.ucr.ac.cr/index.php/rehmlac/article/view/22482/22695; o incluso, véase Pierre-Yves Beaurepaire, "Propuestas para una historia de las prácticas sociales y culturales en el siglo de las Luces”, REHMLAC 5, no. 1 (mayo 2013-noviembre 2013 [citado el 10 de octubre de 2016]): disponible en http://revistas.ucr.ac.cr/index.php/rehmlac/article/view/10361/9748

${ }^{3}$ Véase, Alberto Valín, "Presentación”, en La sociabilidad en la historia contemporánea, dir. Alberto Valín (Ourense: Duen de Bux, 2001), 9-11.

${ }^{4}$ Véase, María Zozaya Montes, "XIV Symposium Internacional de Historia de la Masonería Española: La masonería hispano-lusa y americana. De los absolutismos a las democracias (1815-2015) (Gijón, Centro de Estudios Históricos de la Masonería Española, 2015)", REHMLAC+ 7, no. 2 (diciembre 2015-abril 2016 [citado el 10 de octubre de 2016]): http://revistas.ucr.ac.cr/index.php/rehmlac/article/view/22768/23163

${ }^{5}$ Alicia Alted Vigil y Juan A. Sánchez Belén, Métodos y técnicas de investigación en Historia Moderna e Historia Contemporánea (Madrid: Editorial Centro de estudios Ramón Areces, 2006), 149.

${ }^{6}$ Ya el primer volumen de la conocida serie de libros compiladores de distintos estudios masónicos, The Canonbury Papers, estableció un título sugerente y que viene a reverenciar los lazos estrechos entre este planteamiento historiográfico y la masonería: "The Social Impact of Freemasonry on the Modern Western World".
} 
a las esferas públicas y privadas del ser humano, a la arquitectura y a los espacios, al plano científico, educativo y mitológico, a las tradiciones y a las identidades, a la danza y a la música académica y de tradición oral, y al lógico carácter asociativo, en clarificadora combinación conjunta con el patrimonio cultural ecuménico material e inmaterial de los museos, los archivos y la conjunción artística, el tratamiento transversal de la francmasonería se planteó de forma notable, confirmando que nuestra autora demuestra un amplio conocimiento ${ }^{7}$ sobre esta cuestión.

Igualmente, el comité científico constituido, el cual aceptó las más de cincuenta ponencias presentadas, quedó compuesto por los siguientes integrantes: Jordi Canal (EHESS, CNRS, París), Jean-Louis Guereña (CIREMIA, Tours), Jesús Cruz (Delaware University, USA), Joseba Aguirreazcuenaga (UPV), Beatriz Martínez del Fresno (Universidad de Oviedo), Pere Solà Gussinyer (UAB), Roberto Garvía Soto (Universidad Carlos III de Madrid) y Adrian Shubert (York University, Toronto, Canadá). De todas las presentaciones entroncadas directamente con la francmasonería, como hemos comentado con anterioridad, haremos una breve reseña siguiendo su orden cronológico de aparición.

En el primer día del congreso tuvimos la oportunidad de acercarnos a un tema totalmente novedoso dentro de las exploraciones duales entre las artes y la masonería. Es por lo que, bajo el título "Tras las huellas de las logias: una aproximación al estudio de la cerámica masónica antigua”, el profesor Pelayo Jardón de la UNED nos invitó a sumergirnos en una prueba palpable y evidente de la sociabilidad masónica en los ámbitos personales o grupales de esta esfera privada: las piezas de antigua loza y porcelana que, en las artes decorativas, expresan y refuerzan su sentimiento de identidad y pertenencia a la orden francmasónica. Con la salvedad de las anecdóticas referencias que se presentan frecuentemente en los catálogos de las exposiciones, que por ejemplo en el caso español ${ }^{8}$ suelen utilizar las piezas exhibidas como un mero pretexto de apoyo o adorno a la narración historiográfica, yendo un paso más allá en algunos afortunados $\operatorname{casos}^{9}$, son apenas

\footnotetext{
7 Saberes demostrados indirectamente tanto en su tesis doctoral y sus artículos publicados, como más específicamente en, Zozaya Montes, "Sociabilidad y Fraternidad. Influencias masónicas en la creación de círculos asociativos (1800-1850)", en XII Symposium Internacional de Historia de la Masonería. La masonería española: represión y exilios, coord. José Antonio Ferrer Benimeli (Almería: Universidad de Almería y CEHME, 2010), Tomo II, 1373-1390; y en, Zozaya Montes, “Ante una 'sodality' ibérica. Los nuevos círculos de sociabilidad y la masonería en Portugal y España, 1780-1860" (ponencia presentada en XIV Symposium Internacional de Historia de la Masonería Española: La masonería hispano-lusa y americana. De los absolutismos a las democracias (1815-2015) (Gijón, Centro de Estudios Históricos de la Masonería Española, 2015) [pendiente de publicación]).

${ }^{8}$ Véanse algunos ejemplos como, VV.AA., La masonería por Euskal Herria 1728-1939. Exposición (VitoriaGasteiz: Fundación Caja Vital Kutxa, 1990-1991); Gran Logia de España, La masonería en España. Memoria y razón. Catálogo de la exposición (Getafe: MRA ediciones, 2009); VV.AA., Masonería e Ilustración. Obras del Musée de la Franc-Maçonnerie. Colección GODF (Valencia: Pentagraf, 2009).

${ }^{9}$ Véanse, para el caso y como ejemplo, dos obras dentro del ámbito francés, VV.AA. Museo de la Francmasonería. Colecciones del Gran Oriente de Francia (París: Beaux Arts magazine, 2001); Raphaël Morata, La Franc-Maçonnerie. Les Secrets des Objets (Poitiers: Ch. Massin éditeur, 1990).
} 
inexistentes las referencias extensas y profundas en español sobre estas piezas artísticas en cuanto a su concepción, autoría y utilización ${ }^{10}$. Por ello, no sólo tuvimos la suerte de asistir a lo didáctico de su ponencia en torno a la propia simbología masónica — se trata de un elemento esencial para los neófitos en la materia - sino que, en lo ilustrativo de las imágenes ofrecidas, donde primó la calidad fotográfica de su selección de objetos, refrendamos la utilización de ese lenguaje iconográfico ${ }^{11}$ que emplean los masones como transmisor de ideas $\operatorname{concretas}^{12}$ y esenciales. En definitiva, una aproximación a las lozas marsellesas de Veuve Perrin, a las cerámicas de Doulton, a las estatuillas imbuidas en el rococó de Meissen, a las creaciones de Jingdezhen y Cantón, entre otras, que no sólo vindican su recuerdo y pervivencia en el tiempo ${ }^{13}$, sino que además nos inciden en ese efecto socializador de la utilización de los mismos, especialmente en los ágapes, tal vez, en la interpretación extensa de la cita del escritor y abogado escocés James Boswell cuando afirmó que "una comida lubrica los negocios".

\footnotetext{
${ }^{10}$ Una excepción puede confirmarse con la entrada realizada por el propio profesor Jardón en la página web que sirve como repositorio de investigación al alumnado del Máster de Historia de la Masonería de la UNED, la cual se ha convertido en un importante referente para el estudio de la masonería en sus múltiples enfoques. Además, dicho sea de paso, nuestro autor forma parte del equipo docente de este posgrado. Véase, Pelayo Jardón, Iconografía masónica en la loza francesa antigua, UNED, Museo virtual de historia de la masonería [citado el 10 de octubre de 2016]: disponible en http://www2.uned.es/dptohdi/museovirtualhistoriamasoneria/16Arte y masoneria/lozaantigua.htm

${ }^{11}$ En atención a otras perspectivas que estudian la iconografía y el simbolismo, podemos dejar constancia como ejemplo: desde una somera visión metodológica, véase, María Elena Muñoz Echeverría y María Jesús Ocaña Vázquez, "Aproximación a la iconografía y simbología masónica”, en IV Simposium Internacional de Historia de la Masonería Española. Masonería, revolución y reacción, coord. José Antonio Ferrer Benimeli (Alicante, Instituto Juan Gil-Albert y otros, 1990), Tomo II, 885 - 895; y con una perspectiva más amplia y polivalente, véase, David Martín López, "Arte y masonería: consideraciones metodológicas para su estudio", REHMLAC 1, no. 2 (diciembre 2009-abril 2010 [citado el 10 de octubre de 2016]): disponible en http://revistas.ucr.ac.cr/index.php/rehmlac/article/view/6615/6304; desde las aportaciones de la filatelia, véase Juan Sabater i Pie, "La masonería en Madrid desde la filatelia (1728-2003)", en X Simposium Internacional de Historia de la Masonería Española. La masonería en Madrid y en España del siglo XVIII al XXI, coord. José Antonio Ferrer Benimeli (Leganés, Gobierno de Aragón, 2004), Tomo I, 697-720; e incluso, desde la sigilografía y sus vinculaciones entre política y masonería, véase, Martín Muñoz Zafra, "Introducción a una sigilografía republicano - masónica: Málaga 1887-1937”, en XI Simposium Internacional de Historia de la Masonería Española. La masonería española en la época de Sagasta, coord. José Antonio Ferrer Benimeli (Logroño, Gobierno de Aragón, 2007), Tomo II, 1479-1494; entre otras muchas ejemplificaciones que, además, incluyen el estudio de los monumentos funerarios, el cómic, los trabajos personales de autores masones, etcétera.

${ }^{12}$ Un caso particular se podría vincular al incorporarse algún tipo de lema o divisa que se relacione a la propia orden. Véase esta novedosa perspectiva de estudio en Ferrer Benimeli, Aproximación a la masonería a través de sus lemas y divisas, dir. Yván Pozuelo (Oviedo: Masónica, 2016). Otro caso muy peculiar se conforma en el establecimiento de mensajes escritos mediante la estampación de fragmentos de letras de canciones. Véase como ejemplo esta pieza perteneciente al museo virtual Phoenixmasonry, donde se puede leer una estrofa relativa al texto del conocido himno (constitucional) del aprendiz masón. [Citado el 10 de octubre de 2016]: disponible en http://www.phoenixmasonry.org/masonicmuseum/sunderland lustre pitcher.htm

${ }^{13}$ Una notable aportación al respecto la realizó el profesor Beaurepaire con su entrada sobre los denominados Objetos masónicos. Véase, Beaurepaire, “Objets Maçonniques”, en Dictionnaire de la Franc-maçonnerie, dir. Beaurepaire (París: Armand Colin, 2014), 187-191.
} 
En el mismo sentido de lo visual de la primera ponencia, se confirió la segunda con el título "Rastros visuales de la sociabilidad en la fotografía del Archivo de Salamanca y prensa gráfica". Recordemos que su autora, la profesora Sylvia Hottinger, en calidad de investigadora y colaboradora de la Revista de Estudios Históricos de la Masonería Latinoamericana y Caribeña (REHMLAC+), incansable trabajadora en pro del rescate y la visualización de la mujer ${ }^{14}$ dentro del mundo masónico, concibe su ardua línea de investigación con la utilización de la fotografía ${ }^{15}$ como fuente $^{16}$ de sus pesquisas, acotando su trabajo a la actividad de los teósofos y masones en el período comprendido entre $1889 \mathrm{y}$ 1930. En el establecimiento de varias preguntas de partida en relación a qué se quería mostrar, en qué entorno, con qué fin y para qué destinatarios, la presentación de este trabajo en proceso (y que por fortuna de momento prosigue), envuelve tanto el material existente en el Centro Documental de la Memoria Histórica como la prensa gráfica de dicho lapso temporal, para adentrarse en los momentos de sociabilidad de estos grupos, teniendo por objeto una rememoración más intencional que casual, dado el elevado precio de la propia fotografía. Igualmente, intenta promover una labor prosopográfica relacionada con la autoría de dicho material visual de uso interno e inclusive más externo, donde los propios fotógrafos, masones o no masones, también pueden ser partícipes directa o indirectamente de esa transmisión consciente de ideas.

\footnotetext{
${ }^{14}$ En este sentido, por ejemplo, son frecuentes tanto sus reseñas sobre libros vinculados a la mujer y la masonería en esta revista, como algún artículo biográfico, véase Sylvia Hottinger Craig, "Un contexto para una masona, librepensadora, feminista y republicana: Belén de Sárraga (1872-1950)", REHMLAC 5, vol. 1 (mayo-noviembre de 2013 [citado el 10 de octubre de 2016]): disponible en http://revistas.ucr.ac.cr/index.php/rehmlac/article/view/10358/9747; así como sus ponencias específicas sobre esta cuestión: véanse algunos ejemplos en, Hottinger y María del Pilar Amador Carretero, "Las fotografías de mujeres entre las fotografías de origen masónico del archivo general de la Guerra Civil española", en XII Simposium Internacional de Historia de la Masonería Española. La masonería española. Represión y exilios, coord. Ferrer Benimeli (Almería, Gobierno de Aragón, 2010), Tomo II, 1417-1430; y, Hottinger, "La primera manifestación de mujeres en Barcelona en 1911" (ponencia presentada en XIV Symposium Internacional de Historia de la Masonería Española: La masonería hispano-lusa y americana. De los absolutismos a las democracias (1815-2015) (Gijón, Centro de Estudios Históricos de la Masonería Española, 2015) [pendiente de publicación]).

${ }^{15}$ Especializada en el estudio de la fotografía desde su tesis doctoral, podemos encontrar algunos precedentes en conexión con la masonería tanto en las referencias ya explicitadas (véase cita 14), como en otras autoras: véanse, Blanca Desantes y Margarita Hernández, "Documentación fotográfica masónica en el Archivo Histórico Nacional. Sección Guerra Civil", en VIII Simposium Internacional de Historia de la Masonería Española. La masonería española y la crisis colonial del 98, coord. Ferrer Benimeli (Zaragoza, CEHME, 2010), Tomo I, 141-157; o en los trabajos de la profesora Massé: véase, Patricia Massé, "Invisibilidad y privacidad. Fotografía y masonería en la ciudad de México a finales del siglo XIX" Cuicuilco 14, no. 41 (2007): 169-191.

${ }^{16}$ Indudablemente, estamos ante una valiosa prueba pictórica del pasado que, como afirma la profesora Alted, debe atenderse con un profundo análisis tanto meramente descriptivo como del sentido, la significación y la intencionalidad que trasmite su autoría. Véase, Alted, Métodos y técnicas de investigación en Historia Moderna e Historia Contemporánea, 236-237.
} 
En la segunda jornada del congreso, desarrollada durante el 23 de septiembre, se presentó la tercera de nuestras ponencias descritas: "El Ateneo de Cádiz durante la época de Cayetano del Toro Quartiellers (1842-1915)" del profesor Ángel Guisado, doctorando de la Universidad de Cádiz y miembro ateneísta de la misma ciudad. Su autor, en este caso, presenta las relaciones que existieron entre la vida ejemplar de Papá Cayetano o el Padre del pueblo, en referencia a algunos de los sobrenombres con los que fue conocido el médico y político gaditano Cayetano del Toro y Quartiellers, y su paso como presidente y socio común por el actual Ateneo Literario, Artístico y Científico de Cádiz (antiguo Liceo Científico, Artístico y Literario Gaditano). Y es que este humanista, filántropo y masón gaditano no sólo revitalizó a la propia institución desde su declive a finales del siglo XIX, sino que además extendió su influencia dinamizadora a otras instituciones culturales y cofradías de la propia ciudad, logrando la declaración del Oratorio de San Felipe Neri ${ }^{17}$ como Monumento Nacional y estableciendo numerosos cauces como promotor de la sociabilidad en la ciudadanía de su Cádiz natal. Sin duda, fue una oportunidad para conocer más datos sobre este polifacético personaje ${ }^{18}$ y la labor cultural de los ateneos ${ }^{19}$ en relación con la francmasonería.

El profesor Yván Pozuelo de la IES Universidad Laboral de Gijón, autor de la cuarta ponencia analizada y gran experto en el desarrollo de la masonería en su Asturias natal ${ }^{20}$ nos volvió a sorprender no sólo por su excelente capacidad comunicadora sino por darnos noticias de una de sus líneas de investigación más llamativas e inéditas: la relaciones entre la masonería y las zonas de influencia portuaria junto a los propios barcos. En este sentido, comenzó el ponente con una breve introducción donde enfatizó tanto el trabajo de todos estos años del profesor Ferrer Benimeli desde la creación del CEHME, como la gran labor que realizan todos sus miembros, y que queda reflejada ya sea en la extensa colección bibliográfica que siguen produciendo o igualmente en las actas de sus simposios. Y aunque las limitaciones de tiempo que imperan en este tipo de reuniones científicas dificultaron el iniciar un debate en torno a las reflexiones propuestas por nuestro autor sobre su visión en relación al estudio de la sociabilidad en España ${ }^{21}$, éstas no resultaron indiferentes para el

\footnotetext{
${ }^{17}$ Recordemos que fue la sede de las Cortes de Cádiz de 1812.

${ }^{18}$ Sin dejar atrás numerosas ponencias que han tratado de estudiar a los médicos masones, queremos destacar una novedosa e interesante publicación que saca a colación dicha cuestión (aunque en una época posterior a la del biografiado aludido). Véase, María Victoria Fernández Luceño, Médicos republicanos y masones en Andalucía Contemporánea. La represión franquista. (Sevilla: Aconcagua, 2016).

${ }^{19}$ Véase un ejemplo muy sucinto en, "Masones en el Ateneo de Madrid en el siglo XIX", en XI Simposium Internacional de Historia de la Masonería Española. La masonería española en la época de Sagasta, coord. Ferrer Benimeli (Logroño, Gobierno de Aragón, 2007), Tomo I, 291 - 296.

${ }^{20}$ Véanse, entre otras publicaciones, Pozuelo, La masonería en Asturias (1931-1939) (Oviedo: Universidad de Oviedo, 2012); Pozuelo, Guía histórica de la masonería en Asturias. Tras las huellas de la verdad, (Oviedo: Masónica, 2015).

${ }^{21}$ Es digno de mención que grandes gurús del mundo de la sociabilidad en la historia también participaron en los simposios del CEHME. Véanse los casos de los profesores Jordi Canal i Morell y Jean - Louis Guereña.
} 
público allí congregado. Pero si entramos en la temática y en el título propuesto, "Los puertos, la mar y la masonería”, podemos comprobar, como él mismo afirmó, que no es la primera aproximación que realiza. Recordemos su participación en el libro "La francmaçonnerie dans les ports" y que el propio Ferrer destacó ${ }^{22}$ por lo novedoso; e igualmente, no podemos olvidar sus contribuciones en esta misma publicación ${ }^{23}$. Y aunque hay un lejano precedente en el trabajo que presentó el profesor Ayala ${ }^{24}$ en el primer simposio del CEHME, el corpus manejado por el profesor Pozuelo es bastante más amplio y actualizado, ya que abarca el Reino de España región por región, con la intención (confiemos) de proyectarlo hacia el espacio ibérico. Viajes de ida y vuelta, eternos pasajeros con o sin hogar definido en la búsqueda de una necesaria familiaridad, y momentos de encuentros en torno a la sociabilidad francmasónica, son algunos de los aspectos que se combinan por nuestro ponente con los datos precisos de los ocho mil kilómetros cuadrados de costas, las noventa y nueve localidades portuarias españolas que acogieron al menos una logia y los más de seiscientos talleres masónicos analizados entre los siglos XIX y XX; sin dejar atrás las denominadas logias flotantes y la realidad patrimonial plasmada en numerosos objetos. Miedo y atracción, las dos constantes que nos suscita el mar, también se repitieron en este estudio al hablarnos de la intencionalidad histórica de crear un ente marítimo y masónico superior, asunto que finalmente quedó relegado. En conclusión, un excelso trabajo que Pozuelo delimitó metodológicamente a la perfección, y que esperemos siga dando tan provechosos frutos para un futuro próximo.

La quinta cita nos llegó de la mano del profesor Manuel Según-Alonso, doctorando de la UNED, el cual presentó su intervención titulada: "Una forma de socialización: la masonería madrileña entre 1900 y 1922". Sobre este propósito articuló su ponencia estableciendo un estudio pormenorizado sobre los talleres madrileños Ibérica $n^{\circ}$ 7, la Razón $n^{\circ}$ 142, Montaña, La Cantoniana $n^{\circ} 336$, Condorcet $n^{\circ} 343$, Fuerza Numantina $n^{\circ} 355$, Hispano Americana $n^{\circ} 379$, Life $n^{\circ} 429$, Luís Simarro $n^{\circ} 424$ y la logia de adopción Paz $n^{o}$ 8 , en el rango histórico establecido. Recuérdese que con anterioridad muchos han sido los

\footnotetext{
${ }^{22}$ Nos referimos a la reseña que el profesor Ferrer Benimeli hizo sobre el libro editado por Cécile Révauger y Éric Saunier. Véase Ferrer Benimeli, "La franc-maçonnerie dans les ports, editado por Cécile Révauger y Éric Saunier”, REHMLAC 5, no. 1 (mayo-noviembre 2013 [citado el 10 de octubre de 2016]): disponible en http://revistas.ucr.ac.cr/index.php/rehmlac/article/view/22500/22731

${ }^{23}$ Un claro ejemplo podría ser esta reseña específica: Véase, Pozuelo, "A marinha de guerra portuguesa e a maçonaria de Antonio Ventura", REHMLAC 6, no. 1 (mayo - diciembre 2014 [citado el 10 de octubre de 2016]): disponible en http://revistas.ucr.ac.cr/index.php/rehmlac/article/view/22539/22735

24 Véase, José Antonio Ayala, "Marina y masonería: el ejemplo de Cartagena", en I Simposium de Metodología Aplicada a la Historia de la Masonería Española: la masonería en la historia de España, coord. Ferrer Benimeli (Zaragoza: Diputación General de Aragón y Departamento de Cultura y Educación, 1989), 287-304.
} 
autores $^{25}$ que se han aproximado al caso madrileño desde muy diversas épocas históricas, existiendo, sobre este caso, algún precedente ${ }^{26}$ al respecto. Sin embargo, la virtualidad de este estudio nos propone no sólo establecer quiénes fueron sus miembros y cómo se relacionaron entre sí, sino que, además, y ahí radica otro gran foco de interés, nos avanza hacia cuál fue la posición mantenida ante determinados temas sociales y políticos propios de la época a nivel local, estatal e internacional (Primera Guerra Mundial, librepensamiento, mujer, Iglesia, el mundo obrero, el fusilamiento de Ferrer y Guardia, asuntos sociales...). Y aunque el alejamiento de aquellas cuestiones que pueden romper la hermandad está entre las máximas de la organización, el autor entresaca reflexiones de los documentos históricos manejados que nos dejan palpar un claro posicionamiento ideológico en sentido amplio — son partidarios del reformismo democrático- y en cuestiones partidistas - se congratulan ante el nombramiento de determinadas figuras políticas del momento - Sin duda, una oportunidad para conocer con mayor detenimiento este lapso temporal en la vida masónica madrileña, actualizando su estudio y contemplando una premisa vital en las investigaciones históricas, como dijo en su día el profesor Aróstegui: "Ni la investigación histórica ni ninguna otra depende en exclusiva de la aparición de fuentes de información, sino de explicaciones cada vez más refinadas"27.

Por último, la sexta ponencia, la cual se dedicó a la siempre llamativa proposición de vincular la música con la masonería, y que por fortuna vuelve a resurgir en los últimos $\operatorname{años}^{28}$. En este caso, el profesor Anaya Gámez, doctorando de la Universidad de Málaga,

\footnotetext{
${ }^{25}$ Con sólo asomarnos a las actas de los distintos simposios del CEHME, podemos encontrar desde estudios ceñidos a una logia en concreto, dentro de una franja histórica determinada, hasta sus relaciones con las grandes obediencias, o analizando el papel de la mujer dentro de las mismas.

${ }^{26}$ Es el caso, por ejemplo, de dos investigadoras. Véase, María Teresa Roldán Rabadán, “Cuestiones políticas y sociales tratadas por algunas logias madrileñas", en III Simposium de Metodología Aplicada a la Historia de la Masonería Española. Masonería, política y sociedad, coord. José Antonio Ferrer Benimeli (Zaragoza, CEHME, 1989), Tomo I, 25-33; véase, Olivia Salmón Moviola, "La geopolítica de la masonería en Madrid, 1910 -1936" en IX Simposium Internacional de Historia de la Masonería Española. La masonería española en el 2000, coord. J Ferrer Benimeli (Zaragoza: Gobierno de Aragón, 2001), Tomo I, pp. 505-516; y véase, Olivia Salmón Moviola, La palabra de paso. Identidades y transmisión cultural en la masonería de Madrid (1900-1936), (Santa Cruz de Tenerife: Idea, 2008). Igualmente, y del mismo autor, véase, Manuel SegúnAlonso, "El republicanismo masónico madrileño entre 1923 y 1931: las logias políticas" (ponencia presentada en XIV Symposium Internacional de Historia de la Masonería Española: La masonería hispano-lusa y americana. De los absolutismos a las democracias (1815-2015) (Gijón, Centro de Estudios Históricos de la Masonería Española, 2015) [pendiente de publicación]); y, Según-Alonso "La influencia de la masonería madrileña en la política de la Segunda República Española (1931-1939), REHMLAC 6, no. 2 (diciembre 2014-abril 2015 [citado el 10 de octubre de 2016]): disponible en http://revistas.ucr.ac.cr/index.php/rehmlac/article/view/18199/18426

${ }^{27}$ Julio Aróstegui, La investigación histórica: teoría y método, (Barcelona: Crítica, 2001), 380.

${ }^{28}$ Sobre este particular, queremos destacar dos estudios que relacionan música y masonería, de los cuales esta revista se hizo eco. Véanse, David Vergauwen "Où peut-on être mieux? Masonic music and musicians in 19th - century Brussels", REHMLAC 6, no. 2 (diciembre 2014-abril 2015 [citado el 10 de octubre de 2016]): disponible en http://revistas.ucr.ac.cr/index.php/rehmlac/article/view/18202/18429; y, Juan de Dios López Maya, "Música, Masonería y Poder en la Venezuela del siglo XIX", REHMLAC+ 8, no. 1 (mayo-noviembre
} 
presentó su ponencia "De la canción callejera al himno fraternal: breve aproximación al pasado y al presente de la música cantada en los contextos masónicos de sociabilidad". Si bien, la música en vivo procurada precedió a sus palabras y formó parte de unos de sus objetivos finales, o lo que es lo mismo, la reconstrucción de una melodía de la época bonapartista asimilada a masónica, su meta sigue vinculada a la línea de investigación que otros autores ya anticiparon: las posibles imbricaciones entre música y literatura ${ }^{29}$ en el contexto francmasónico. Además, con este breve estudio histórico-descriptivo planteado entre lo que fue la música cantada dentro de los contextos de sociabilidad en la masonería a nivel europeo, asentando la base de subrayar su verdadero origen patrimonial vinculado al pueblo y la tradición oral, estableció finalmente posibles nexos de unión con una muy diferente situación actual ${ }^{30}$. En conclusión, nuestra música, un instrumento de unión colectiva $^{31}$, que ensalza los sentimientos de férrea identificación y hermandad, junto a los posibles valores intrínsecos, y que el ponente asemejó a los vividos con tanta cordialidad en los momentos de esparcimiento e intercambio de ideas vivenciados en las veladas de este congreso.

\section{Conclusión}

En resumen, hemos esbozado lo acontecido en estas seis ponencias directamente relacionadas con la masonería y que se presentaron en el contexto del Congreso Internacional SocyHume del CIDEHUS de la Universidad de Évora. Un encuentro científico de amplia relevancia, del que confiemos surjan nuevas ediciones, tal vez dando la oportunidad a que grandes figuras de la historiografía masónica aporten su visión ante esta línea de trabajo en vinculación con la sociabilidad, y que, en definitiva, siempre nos invite a reflexionar sobre lo espléndido que fue esta cita en Évora y las sabias palabras de Marco

\footnotetext{
2016 [citado el 10 de octubre de 2016]): http://revistas.ucr.ac.cr/index.php/rehmlac/article/view/24278/24853

29 Véanse, Trevor Steward (ed.), Freemasonry in Music and Literature. The Canonbury Papers. v. 2, (Londres, Canonbury Masonic Research Centre, 2003); Jeffrey Tyssens, "Félix Bovie (1812-1880): poète et chansonnier dans la franc-maçonnerie bruxelloise", REHMLAC 5, no. 2 (diciembre 2013-abril 2014 [citado el 10 de octubre de 2016]): disponible en http://revistas.ucr.ac.cr/index.php/rehmlac/article/view/12935/12231; y, Fernando Anaya Gámez, "Y la lira volvió a sonar: breve estudio sobre las relaciones semánticas entre música y masonería", (ponencia presentada en XIV Symposium Internacional de Historia de la Masonería Española: La masonería hispano-lusa y americana. De los absolutismos a las democracias (1815-2015) (Gijón, Centro de Estudios Históricos de la Masonería Española, 2015) [pendiente de publicación]).

${ }^{30}$ Véase, Honorio Marcial, Columna de armonía. Guía para los hermanos de la Tercera Columna (Oviedo: Masónica, 2014).

${ }^{31}$ Es interesante destacar cómo los estudios de la sociabilidad también se han decantado en los primeros momentos por el análisis de la música en los contextos colectivos. Véase, Jean-Louis Guereña (coord.) "Sociétés musicales et cantantes en Espagne (XIXe-XXe siècle)", Bulletin d'Histoire Contemporaine de l'Espagne, no 20 (1994): 31-140; y véase, Jaume Carbonell i Guberna, "Aportaciones al estudio de la sociabilidad coral en la España Contemporánea”, Hispania, LXIII/2 no. 214 (2003): 485-504.
} 
Tulio Cicerón: "El placer de los banquetes debe medirse no por la abundancia de los manjares, sino por la reunión de los amigos y por su conversación". De la teoría a la práctica, de la sociabilidad al hermanamiento ante la historia.

\section{Anexo documental}

\section{2 de septiembre de 2016.}

Sociabilidad, museos y patrimonio:

Pelayo Jardón (UNED): “Tras las huellas de las logias: una aproximación al estudio de la cerámica masónica antigua".

Patrimonio archivístico y fotográfico:

Sylvia Hottinger (REHMLAC+): "Rastros visuales de la sociabilidad en la fotografía del Archivo de Salamanca y prensa gráfica".

\section{3 de septiembre de 2016}

Asociacionismo en los siglos XIX y XX:

Ángel Guisado Cuéllar (Universidad de Cádiz): "El Ateneo de Cádiz durante la época de Cayetano del Toro Quartiellers (1842-1915)”.

Patrimonio ecuménico y masonería:

Yván Pozuelo (Universidad Laboral de Gijón): "Los puertos, la mar y la masonería".

Manuel Según-Alonso (UNED): “Una forma de socialización: la masonería madrileña entre 1900 y $1922 "$.

\section{4 de septiembre de 2016}

Sociabilidad con música y danza:

Fernando Anaya Gámez (Universidad de Málaga): "De la canción callejera al himno fraternal: breve aproximación al pasado y al presente de la música cantada en los contextos masónicos de sociabilidad". 